\title{
Presentation modality, rehearsal-prevention conditions, and auditory confusions in tests of short-term memory*
}

\author{
JANET T. THOMPSON $\dagger$ and KEITH N. CLAYTON \\ Vanderbilt University, Nashville, Tennessee 37203
}

\begin{abstract}
Ss were presented four-letter sequences either auditorily or visually and asked for ordered recall after $0,2.1,4.2,8.4$, or 12.6 sec of digit categorization. Three different rehearsal-prevention conditions were required during presentation of the memory set: categorizing, suppressing (saying "ah"), or pronouncing each letter. Recall was worst after categorizing, best after pronouncing. Auditory presentation led to better recall after no delay but more rapid forgetting than visual presentation, regardless of the rehearsal-prevention condition. These results, and analyses of auditory confusions, are inconsistent with a view of memory which asserts that sensory information is encoded auditorily regardless of presentation modality or vocalization behavior during presentation.
\end{abstract}

Two conceptualizations of the status of information in postperceptual memory have emerged in contemporary theories of verbal memory. According to one notion, the recoding conceptualization, information in sensory stores is recoded by a central processor on auditory dimensions and placed in an auditory short-term store. Recoding occurs independently of peripheral factors such as mode of input, so that information is represented along auditory dimensions regardless of its original input mode (Sperling, 1967). The alternative, multitrace, conceptualization asserts that information is coded along several dimensions, so that what exists in postperceptual memory is a collection of attributes. Although several versions of this view have been advanced (Bower, 1967; Underwood, 1969), this paper will deal with the version discussed by Estes (1970b, 1973), because it differs most evidently from the recoding view. Specifically, according to Estes's treatment, sensory information for a modality is essential to trace formation. For example, if information is presented visually, the $S$ must rehearse, subvocally or vocally, to provide the sensory information necessary for coding along the auditory dimension.

The present experiment was stimulated by a recent effort by Estes to test between these two views. His research was reported in two phases. First, Estes (1970a) replicated a study by Conrad (1967), who tested the retention of visually presented letter sequences after either 2.4 or $7.2 \mathrm{sec}$ and found that the probability of auditory confusion errors decreased with time, from .59 at the 2.4-sec interval to .38 (compared to .31 chance level) at the 7.2-sec interval. In Estes's (1970a) replication, retention was tested after 1.2, 2.4, 4.8, 7.2, and $12.0 \mathrm{sec}$ and the probability of auditory confusion

\footnotetext{
*This paper is based on a dissertation submitted by the first author to Vanderbilt University in partial fulfillment of the requirements for the $\mathrm{PhD}$ degree. The research was supported in part by National Institute of Mental Health Grant MH 19950.

$+R$ equests for reprints should be sent to Janet Thompson, 425 Hillary Street, New Orleans, Louisiana 70118.
}

errors was maximal at $2.4 \mathrm{sec}$ and decreased steadily to $12.0 \mathrm{sec}$. Both the recoding and the multitrace notions can handle these results, since Ss were verbalizing the visual stimuli as they were presented. However, Estes argued that if the formation of an auditory trace requires sensory information from the auditory mode, then auditory confusions should not occur if verbalization of visually presented items is prevented. To test this prediction, Estes (1970b) repeated the (1970a) experiment but prevented verbalization by requiring Ss to categorize the stimuli aloud. The Ss required to categorize were found to make few auditory confusion errors, and percent of auditory confusion errors did not change over retention interval as it had in the previous study. Additionally, the proportion of errors that were auditory confusions was near chance level for all retention intervals. Estes concluded that these data supported the multitrace view and not the recoding view. The multitrace view was further supported in a follow-up study (1973) in which Estes tested in the same study the retention of visually presented sequences of letters that were either pronounced or categorized by the $\mathrm{S}$.

The recoding interpretation, however, may not have received a critical test by Estes's experiments. If recoding is performed by some central processor which has finite capability and if the central processor is also involved in the categorization activity, then recoding may have been prevented or impaired by the addition of the categorization requirement. The failure to find auditory confusion errors may therefore merely reflect inadequate or incomplete processing and cannot be taken as damaging evidence for this modified recoding view.

The present experiment replicated Estes's (1970b) study in most procedural aspects while extending the study to provide a stronger test of the two models. It seemed that a stronger test required a situation where Ss were provided, via auditory presentation, with the sensory information necessary for an auditory trace and 
were also required to participate in a time-consuming task. In this situation the modified recoding view would have to predict that the task would prevent recoding, as before, and auditory confusion errors would be minimal, as before. On the other hand, the multitrace view would predict auditory confusion errors, since auditory presentation should be sufficient for forming an auditory trace.

In addition to the categorization task used by Estes, a rehearsal-prevention task similar to that used by Murray (1968) was utilized. With this procedure, Ss simply say "ah" as each letter is presented. In terms of time-consumption requirements, this "suppression" task should be intermediate between the verbalization and categorization tasks. In addition, an immediate recall test was added to those used by Estes to ensure that any very rapid initial change in error probabilities could be detected.

Thus the overall design for the study is a 2 (two presentation modes-auditory and visual) by 3 (rehearsal-prevention groups-pronounce, suppress, and categorize) by 5 (retention intervals $-0,2.1,4.2,8.4$ and $12.6 \mathrm{sec}$ ) factorial.

\section{METHOD}

\section{Subjects}

Six Vanderbilt graduate students served as Ss. Each S participated on 7 consecutive days, including an initial training session and six experimental sessions. All Ss were paid for their participation.

\section{Procedure}

During the first session, each of the Ss participated in a 1-h training session for categorization. Each of two lists, composed of series of letters, numbers, and practice trials, was presented first visually and then auditorily. At this session, the general nature of the training task and of the tasks on the days to follow was explained to the Ss. For the categorization task Ss were instructed to say aloud "low" for the letters A-M and for the digits 1-4 and "high" for the letters $\mathrm{N}-\mathrm{Z}$ and the digits 5-9. For the pronounce condition $S s$ were instructed to say aloud each letter as it was presented. For the suppress condition Ss were instructed to say "ah" as each letter was presented. The Ss were further instructed to say the letter name category or "ah" only once for each letter and to pace their response so that the pronunciation of the letter name, category, or "ah" filled the presentation interval. For all conditions the Ss were instructed to categorize the intervening digits and to respond continuously, not correcting errors.

During the experiment proper, each of the Ss served in the six conditions formed by combining three groups-categorize, suppress, and pronounce-with two presentation modes -visual and auditory. The Ss were tested individually on 6 consecutive days, serving in a different condition each day. Each $S$ was tested on each sequence order and received a different random ordering of the sequence orders and the conditions. Each sequence was paired with each condition.

Each experimental session consisted of the presentation of 110 sequences, 10 practice sequences and 100 test sequences. The letters of each sequence, which were four letters long, were presented sequentially followed by either a signal for immediate recall or by a series of $3,6,12$, or 18 intervening digits, followed by a signal for recall. For recall, Ss attempted to write each letter in the correct position on the response booklet, filling in all blanks, by guessing if necessary. All guesses were to be circled. Approximately $15 \mathrm{sec}$ were allowed for recall. A 30 -sec break followed each block of 5 sequences and a 1-min break followed each block of 20 sequences. All Ss were told that they were participating in a study of short-term memory. On each day, instructions specific to the condition for that day were given.

\section{Materials}

For the categorization training session, two lists were constructed of series of letters, digits, and practice trials. The series of letters, ranging from 2 to 10 letters in length, were selected from the vocabulary of letters (BCPTV FSX NM). Within the vocabulary of letters, selected on the basis of previous research by Conrad $(1962,1964,1967)$ and Wickelgren $(1965 \mathrm{a}, \mathrm{b})$, letters within each grouping (e.g., B and T) were more likely to be confused than letters across groupings (e.g., F and T). Several random orderings of the total set of digits (1-9) were selected. Finally, trials of each retention interval type were constructed (see description below). For each list the series of letters progressed from the shorter to the longer series, followed by the series of numbers and finally the practice trials, also progressing from the shorter to the longer trials.

For both the training and the experimental sessions, 4-letter sequences were constructed by randomly assigning letters from the vocabulary of 10 (BCPTV FSX NM) with the constraint that no letter occur more than once in a sequence or in the same position in 2 consecutive sequences. A total of 110 sequences were thus constructed. The total set was broken into 10 practice sequences and five blocks of 20 test sequences. Within each block of 20 sequences, each of the five retention intervals was tested four times in a randomly determined order. Further, within each block of 20 , each letter in the vocabulary occurred equally of ten in each position. Six different presentation orders were constructed by varying the order of the blocks.

The Ss recorded their recall responses in booklets containing one page per sequence. The vocabulary was printed on the top of each page. Immediately below were four blanks, one for each letter to be recalled.

\section{Apparatus}

For the auditory presentation conditions, the stimulus sequences had been recorded on magnetic tape with a Sony stereophonic tape recorder. A trained speaker had read each letter and each digit. For the initial part of the training session, each item was read at a rate of $700 \mathrm{msec}$ followed by a $30-\mathrm{msec}$ pause. For the second part of the training session and all of the experimental sessions, each item was read at a rate of $700 \mathrm{msec}$ with no pause between items. A high tone $(600 \mathrm{cps})$ signaled the beginning of each sequence. For immediate recall the fourth letter of the sequence was followed by a low tone $(60 \mathrm{cps})$ to signal recall. For all other retention intervals, the fourth letter was followed by the appropriate number of digits, then the signal for recall.

For the visual presentation conditions, the letters and digits had been typed in primary type on $3 \times 5$ in. cards with an IBM executive typewriter. A Bolex movie camera had been used to photograph the cards on black and white $16-\mathrm{mm}$ film. The film was presented with a step projector. For the initial part of the training session, each letter and each digit was exposed for $500 \mathrm{msec}$. For the second part of the training session and all of the experimental sessions, each letter and each digit was exposed for $500 \mathrm{msec}$ followed by a frame of random dots for $200 \mathrm{~m} \mathrm{sec}$. A frame with three asterisks indicated the beginning of each sequence. For immediate recall, a frame with three question marks followed the fourth letter to signal recall. For all other retention intervals, the appropriate number of digits followed the fourth letter, then the signal for recall.

\section{RESULTS AND DISCUSSION}

\section{Categorization Performance}

To determine whether recall errors were errors of 
Table 1

Mean Number of Correct Responses and Corresponding Standard Errors

\begin{tabular}{|c|c|c|c|c|c|c|c|c|c|c|c|c|}
\hline \multirow[b]{4}{*}{$\begin{array}{l}\text { Delay } \\
\text { (Sec) }\end{array}$} & & \multicolumn{6}{|c|}{ Modality } & & & & & \\
\hline & & \multicolumn{3}{|c|}{ Auditory } & \multicolumn{3}{|c|}{ Visual } & & & & & \\
\hline & & \multicolumn{3}{|c|}{ Rehearsal Prevention } & \multicolumn{3}{|c|}{ Rehearsal Prevention } & \multicolumn{3}{|c|}{ Rehearsal Prevention } & \multicolumn{2}{|c|}{ Modality } \\
\hline & & $\begin{array}{l}\text { Cate- } \\
\text { gorize }\end{array}$ & $\begin{array}{l}\text { Sup- } \\
\text { press }\end{array}$ & $\begin{array}{c}\text { Pro- } \\
\text { nounce }\end{array}$ & $\begin{array}{l}\text { Cate- } \\
\text { gorize }\end{array}$ & $\begin{array}{l}\text { Sup- } \\
\text { press }\end{array}$ & $\begin{array}{c}\begin{array}{c}\text { Pro- } \\
\text { nounce }\end{array} \\
\end{array}$ & $\begin{array}{l}\text { Cate- } \\
\text { gorize }\end{array}$ & $\begin{array}{l}\text { Sup- } \\
\text { press }\end{array}$ & $\begin{array}{c}\text { Pro- } \\
\text { nounce }\end{array}$ & Auditory & Visual \\
\hline 0 & $\begin{array}{l}\text { Mean } \\
\text { SE }\end{array}$ & $\begin{array}{r}67.67 \\
4.71\end{array}$ & $\begin{array}{r}72.83 \\
2.33\end{array}$ & $\begin{array}{r}77.33 \\
0.72\end{array}$ & $\begin{array}{r}58.17 \\
7.29\end{array}$ & $\begin{array}{r}65.50 \\
6.85\end{array}$ & $\begin{array}{r}78.33 \\
0.95\end{array}$ & 62.92 & 69.17 & 77.83 & 72.61 & 67.33 \\
\hline 2.1 & $\begin{array}{l}\text { Mean } \\
\text { SE }\end{array}$ & $\begin{array}{r}31.00 \\
6.58\end{array}$ & $\begin{array}{r}39.50 \\
3.61\end{array}$ & $\begin{array}{r}47.50 \\
4.37\end{array}$ & $\begin{array}{r}43.83 \\
9.33\end{array}$ & $\begin{array}{r}53.17 \\
8.17\end{array}$ & $\begin{array}{r}67.00 \\
4.66\end{array}$ & 37.42 & 46.33 & 57.25 & 39.33 & 54.67 \\
\hline 4.2 & $\begin{array}{l}\text { Mean } \\
\text { SE }\end{array}$ & $\begin{array}{r}16.17 \\
5.16\end{array}$ & $\begin{array}{r}20.17 \\
4.92\end{array}$ & $\begin{array}{r}33.17 \\
8.62\end{array}$ & $\begin{array}{r}34.00 \\
7.26\end{array}$ & $\begin{array}{r}44.00 \\
8.02\end{array}$ & $\begin{array}{r}61,50 \\
6.10\end{array}$ & 25.08 & 32.08 & 47.33 & 23.17 & 46.50 \\
\hline 8.4 & $\begin{array}{l}\text { Mean } \\
\mathrm{SE}\end{array}$ & $\begin{array}{r}12.00 \\
4.11\end{array}$ & $\begin{array}{r}17.33 \\
4.14\end{array}$ & $\begin{array}{r}26.83 \\
6.41\end{array}$ & $\begin{array}{r}33.33 \\
5.40\end{array}$ & $\begin{array}{r}48.33 \\
5.80\end{array}$ & $\begin{array}{r}51.50 \\
7.62\end{array}$ & 22.67 & 32.83 & 39.17 & 18.72 & 44.39 \\
\hline 12.6 & $\begin{array}{l}\text { Mean } \\
\text { SE }\end{array}$ & $\begin{array}{l}9.83 \\
4.44\end{array}$ & $\begin{array}{r}14.83 \\
4.03\end{array}$ & $\begin{array}{r}13.67 \\
4.30 \\
\end{array}$ & $\begin{array}{r}24.00 \\
7.47\end{array}$ & $\begin{array}{r}43.00 \\
9.59 \\
\end{array}$ & $\begin{array}{r}41.17 \\
7.69 \\
\end{array}$ & 16.92 & 28.92 & 27.42 & 12.78 & 36.06 \\
\hline
\end{tabular}

Note-The first six columns report the data for all conditions in the experiment. The maximum possible score is 80 , since each $S$ received 20 sequences of four letters in each condition. The last five columns present the data collapsed over Modality (next three columns) or Rehearsal-Prevention Condition (last two columns) and the means are calculated in such a way that 80 remains the maximum possible mean.

memory or perception, all categorization was checked. The average error rate for categorizing letters for the auditory categorize and the visual categorize conditions was $.25 \%$ and $.21 \%$, respectively. The error rate for categorizing digits ranged from $3.78 \%$ for the auditory categorize to $.26 \%$ for the visual pronounce conditions. It is clear that Ss were almost always perceiving both the letters and the digits correctly.

\section{Frequency Correct in Recall}

Analyses were performed separately on responses designated by each $\mathrm{S}$ as guesses and as nonguesses. This procedure was used so that the data could be compared with both Conrad (1967), who forced each $S$ to guess but did not ask to indicate which were guesses, and with Estes $(1970 \mathrm{a}, \mathrm{b})$, who asked his Ss to omit responses if they were not sure. However, the conclusions reached here do not depend on which data are analyzed, so only the nonguess data are reported.

The means and standard errors for each condition are presented in the first six data columns of Table 1. An analysis of variance of the frequencies correct revealed significant main effects of rehearsal prevention $[F(2,10)$ $=7.04, p<.01]$ and delay $[F(4,20)=132.98, p<.01]$. The significant Rehearsal Prevention by Delay interaction $[F(8,40)=2.71, p<.05]$ is shown in the data of Columns 7.9 of Table 1 , where it can be seen that at short delays, performance was superior for the pronounce condition, followed by the suppress and categorize conditions, and that at long delays, performance for the suppress and pronounce conditions was equivalent, with performance for the categorize condition somewhat lower. Rehearsal-prevention conditions were planned so that ease of rehearsal would be affected differentially. That is, Ss in the pronounce condition were expected to have more time to rehearse than Ss in the suppress condition. Similarly, Ss in the suppress condition were expected to have more time to rehearse than $S s$ in the categorize condition. Consequently, $\mathrm{Ss}$ in the pronounce condition were expected to perform better than those in the suppress condition and $S s$ in the suppress condition were expected to perform better than those in the categorize group. Rehearsal prevention affected performance in the manner expected.

The analysis of variance also revealed a significant main effect of presentation modality $[F(1,5)=10.32$, $p<.05]$ as well as a significant Modality by Delay interaction $[F(4,20)=19.75, p<.01]$. This interaction is shown in the last two columns of Table 1, where it can be seen that an auditory superiority at 0 sec delay is replaced by superior performance for the visual presentation condition at the longer delays. The superior performance for auditory presentation at short delays was expected on the basis of previous studies (e.g., Cooley \& McNulty, 1967; Grant \& McCormack, 1969; Murdock, 1966, 1967, 1968) of modality effects in short-term memory. Such studies report superior performance for auditorily presented information at short intervals. Several investigators (e.g., Crowder \& Morton, 1969; Kroll et al, 1972; Murdock \& Walker, 1969; Parkinson, 1972; Peterson \& Johnson, 1971; Salzberg et al, 1971) have suggested that the superiority of auditory over visual presentation may be explained by a relatively long-lasting ( $2 \mathrm{sec}$ or more) echoic memory for auditory information. At short intervals, information may be taken directly from the echoic memory, aiding performance for information received in that modality. The results of this study corroborate the results of those studies and are consistent with the notion of a relatively long-lasting echoic store.

More relevant, yet not critical, to the recoding and 


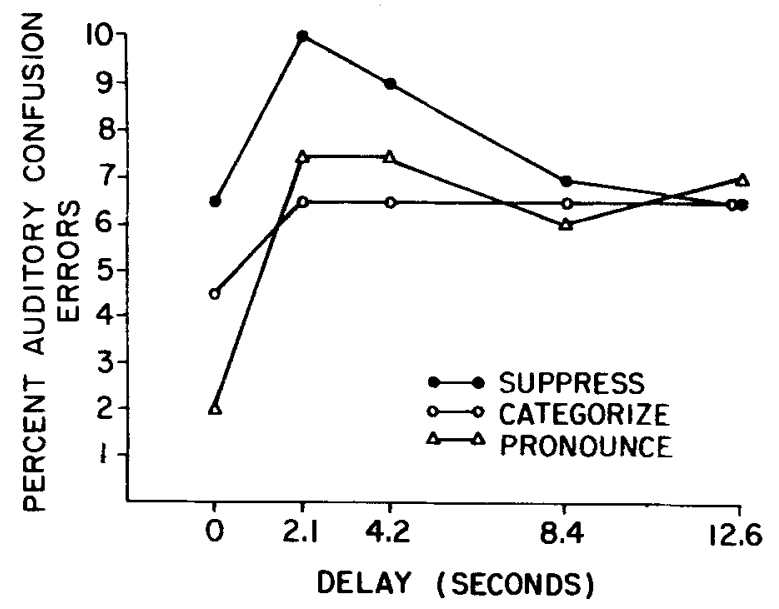

Fig. 1. Percent of nonguess responses that were auditory confusion errors for each rehearsal-prevention condition.

multitrace comparison were the differential decay rates observed for auditorily and visually presented information (Table 1). Although retention of auditorily presented information was superior at the 0 -sec interval, retention of visually presented information was much superior at the $12.6-\mathrm{sec}$ interval. Several other investigators (e.g., Kroll et al, 1972; Parkinson, 1972; Peterson \& Johnson, 1971; Salzberg et al, 1971) have reported similar results. The recoding view cannot handle this data because input modality is assumed, by this view, to be unimportant. All information is recoded along auditory dimensions, and input modality should not affect decay rate. For the multitrace view, however, input modality is important, and differential decay rates for auditory and visually presented information are possible.

It might be argued that the modality difference merely reflects differential opportunity for rehearsal for the auditory and visual presentation conditions. That is, when presentation rate is held constant in a comparison of visual and auditory presentation, as it was in the present study, Ss may encode the visual information more rapidly and thereby have a longer duration of time between presentations to rehearse. If this explanation of the modality effect were correct, however, it follows that the size of the effect should be greatest under those rehearsal-prevention conditions which permitted the most rehearsal and least, or absent, under those conditions which virtually eliminated rehearsal. In other words, this explanation requires either a significant Rehearsal-Prevention Condition by Modality interaction or a triple interaction involving those two variables with delay. Neither interaction is significant $[\mathrm{F}(2,10)=.88$ and $F(8,40)=1.05$, respectively]. Thus, an account of the modality effect in terms of rehearsal differences does not seem appropriate for the present results.

\section{Auditory Confusion Errors}

All errors were classified according to type of confusion. Auditory confusion errors were errors in which a letter from the confusion set of the correct letter was substituted for the correct letter; nonconfusion errors included all cases where a letter outside the confusion set of the correct letter was substituted for the correct letter. For those rare cases where the $S$ incorrectly categorized the letter or for any reason did not respond, the average response for that condition was used. An analysis of variance on frequency of nonguess responses that were auditory confusion errors revealed no significant main effect of rehearsal prevention, but it interacted significantly with delay $[F(8,40)=2.15, p<.05]$. As can be seen in Fig. 1, the frequency of auditory confusion errors for all conditions converged over time. Both the multitrace and the recoding view would predict this convergence.

Significant main effects for modality $[F(1,5)=8.34$, $\mathrm{p}<.05]$, delay $[\mathrm{F}(4,10)=3.08, \mathrm{p}<.05]$, and the Modality by Delay interaction $[F(4,20)=4.94, p<.05]$ were found. Generally, Ss made more auditory confusion errors with auditory presentation than with visual presentation. As can be seen in Fig. 2, with auditory presentation (but not visual) auditory errors first increased then decreased over time. The results shown in Fig. 2 held over all rehearsal-prevention conditions. That is, there was no significant Modality by Rehearsal-Prevention by Delay interaction.

The observed initial increase and subsequent decrease of auditory confusion errors for all auditory presentation conditions regardless of rehearsal-prevention condition is consistent with the multitrace view and inconsistent with the recoding view. Remember that, according to the multitrace view, presentation of information by the auditory mode is sufficient for the formation of an auditory trace and the resulting auditory confusion errors. According to the recoding view, on the other hand, central processor

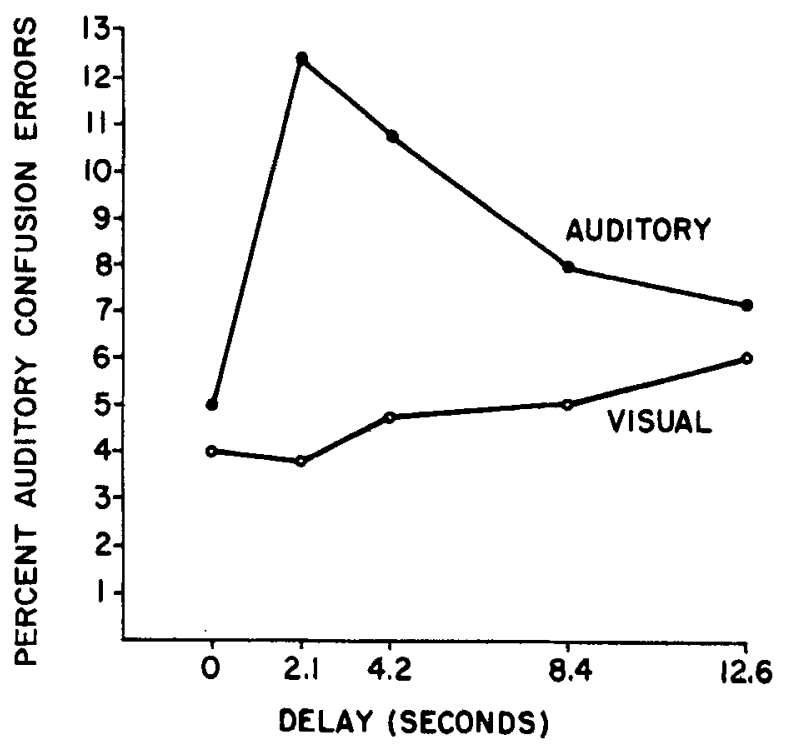

Fig. 2. Percent of nonguess responses that were auditory confusion errors for auditory and visual presentations. 
activity is more important than mode of input. If Estes's (1970b) failure to obtain auditory confusions resulted from a failure to recode when the central processor was overloaded by the time-consuming rehearsal-prevention condition, then the result shown in Fig. 2 should depend on the rehearsal-prevention condition. This was not observed. While the rehearsal-prevention task did influence recall performance, auditory confusions of the type Estes (1970a) and Conrad (1967) reported can occur if the items are presented in the auditory modality. Apparently an auditory trace is formed so long as the auditory modality is used, or if the $S$ vocalizes or subvocalizes the item. There is no evidence that an auditory representation in memory is achieved in any other way,

\section{REFERENCES}

Bower, G. H. A multicomponent theory of the memory trace. In K. W. Spence and J. T. Spence (Eds.), Advances in the psychology of learning and motivation research and theory. Vol. I. New York: Academic Press, 1967. Pp. 229-235.

Cooley, R. K., \& McNulty, J. A, Recall of individual CCC trigrams over short intervals of time as a function of mode of presentation. Psychonomic Science, 1967, 9, 543-544.

Conrad, R. An association between memory errors and errors due to acoustic masking of speech. Nature, 1962, 163, 1314-1315.

Conrad, R. Acoustic confusions in immediate memory. British Journal of Psychology, 1964, 55, 77-84.

Conrad, R. Interference or decay over short retention intervals? Joumal of Verbal Learning \& Verbal Behavior, 1967, 6 , 49-54.

Crowder, R. G \& Morton, J. Precategorical acoustic storage (PAS). Perception \& Psychophy sics, 1969, 5, 365-373.

Estes, W. K. Evaluation of some models of acoustic confusion effects in short-term memory. In Communications in Mathematical Psychology, Technical Report Series, The Rockefeller University, October, 1969-March 1970a, 1-16.

Estes, W. K. On the source of acoustic confusions in short term memory for letter strings. In Communications in Mathematical Psychology, Technical Report Series, The Rockefeller University, April 1970-Debember 1970b, 1-22.
Estes, W. $K$. Phonemic coding and rehearsal in short-term memory for letter strings. Journal of Verbal Learning \& Verbal Behavior, 1973, 12, 360-372.

Grant, K. W., \& McCormack, P. D. Auditory and visual short-term memory with successive syllable presentation in both modalities. Psychonomic Science, 1969, 17, 341-342.

Kroll, N. E. A., Parkinson, S. R., \& Parks, T. E. Sensory and active storage of compound visual and auditory stimuli. Journal of Experimental Psychology, 1972, 95, 32-38.

Murdock, B. B., Jr. Visual and auditory stores in short-term memory. Quarterly Journal of Experimental Psychology, $1966,18,206-211$.

Murdock, B. B., Jr. Auditory and visual stores in short-term memory. Acta Psy chologica, 1967, 27, 316-324.

Murdock, B. B., Jr. Modality effects in short-term memory: Storage or retrieval? Joumal of Experimental Psychology, $1968,77,79-86$

Murdock, B. B., Jx., \& Walker, K. D. Modalíty effects in free recall. Journal of Verbal Learning \& Verbal Behavior, 1969, 8, 665-676.

Murray, D. J. Articulation and acoustic confusability in short-term memory. Journal of Experimental Psychology, $1968,78,679-684$.

Parkinson, $S$. R. Short-term memory while shadowing: Multiple-item recall of visually and aurally presented letters. Journal of Experimental Psychology, 1972, 92, 25 8-265.

Peterson, L. R., \& Johnson, S. T. Some effects of minimizing articulation on short-term retention. Joumal of Verbal Learning \& Verbal Behavior, 1971, 10, 346-354.

Salzberg, P. M., Parks, T. E., Kroll, N. E. A., \& Parkinson, S. R. Retroactive effects of phonemic similarity on short-term recal of visual and auditory similarity. Journal of Experimental Psychology, 1971, 91, 43-46.

Spering, G. A. Successive approximations to a model for short-term memory. Acta Psy chologica, 1967, 27, 285-292.

Underwood, B. J. Attributes of memory. Psychological Review, $1969,76,559-573$

Wickelgren, W. A. Acoustic similarity and intrusion errors in short-term memory. Journal of Experimental Psychology, $1965 \mathrm{a}, 70,102-108$.

Wickelgren, W. A. Acoustic similarity and retroactive interference in short-term memory. Jounal of Verbal Learning \& Verbal Behavior, $1965 b, 4,53-61$.

(Received for publication August 28, 1973; revision received November 12,1973 .) 